\title{
A NUMERICAL SIMULATION OF SEPARATION OF CROP SEEDS BY SCREENING-EFFECT OF PARTICLE BED DEPTH
}

\author{
J. LI, C. WEBB, S. S. PANDIELLA and G. M. CAMPBELL \\ Satake Centre for Grain Process Engineering, Department of Chemical Engineering, UMIST, Manchester, UK.
}

$\mathrm{E}$ ffective separation and grading of cereal grains and crop seeds are of importance in the production of quality cereal foods. This paper presents a two-dimensional numerical study of the separation process of crop seeds by screening, using the Discrete Element Method (DEM) modelling technique. Computational experiments have been conducted for the separation of two common crop seeds, soybeans and mustard seeds, using a vibrating screen. The screening rate and the required screen length at different feeding rates are discussed in relation to the discrete particle motion on the screen. This study has demonstrated the crucial effect of particle bed depth on screening efficiency. For a screening system involving granular materials, the critical feeding rate for the most effective screening operation can be determined via conducting the DEM simulation.

Keywords: cereal/crop seed; screening; size segregation; particle bed depth; DEM model; numerical simulation.

\section{INTRODUCTION}

Separation of cereal grains and crop seeds from impurities, such as sands and stones, lumps of earth, glass fragments and weed and other crop seeds, is an important process in cereal and food processing and grain and oilseed trading ${ }^{1}$. In a flour milling plant, for example, there are various cleaning operations, such as aspiration, destoning and magnetic separation, which are employed to separate impurities from wheat grains according to their differences in aerodynamic and physical properties, e.g. size, shape and density. Among these operations, screening is widely used to remove larger foreign materials such as stones and lumps of earth and smaller impurities such as sands and other crop seeds ${ }^{2}$.

The size separation of particles by screening is by no means new to chemical and food engineers. Coulson and Richardson ${ }^{3}$ state that sieving or screening has been widely used in industries, as a unit operation for the large-scale separation of particles according to sizes, and in laboratories, as a tool for the analysis of particle size distribution, usually at a small scale. Industrial operations using sieves or screens have spread into a variety of engineering categories, from traditional mineral and metallurgical engineering to the contemporary, fast growing categories of food and pharmaceutical engineering. Standish ${ }^{4}$ states that sieving is probably the oldest and most widely employed physical size separation method. Nevertheless, due to the complex nature of industrial particulate materials, such as the complicated size distribution and composition, and the lack of advanced mathematical and experimental techniques practically applicable to the study of particulate systems, the physical understanding of this complex engineering process has never been realized. As a result, most published information on sieve and screen performance has been empirical in nature ${ }^{5}$ and industrial screening charts and formulae have proven very inaccurate and can produce results that vary by a factor of three ${ }^{4}$. Obviously, the subject has not been well understood.

Most of the early works on sieving concern the establishment of factors influencing the screening rate $e^{5-7}$ and analyses of sieving kinetics ${ }^{8}$. These analyses are usually based on experimental data from conducting practical sieving operations via the weighing of the overflow (passing onto the end of the screen) and underflow (passing through the screen mesh) streams. Mathematical models are produced by the application of probability theories, e.g. Kaye and Robb ${ }^{8}$, Subasinghe et al. ${ }^{9}$ and more recently Grozubinsky et al. ${ }^{10}$. However, these probabilistic models fail to account for the effect of the microscopic particle motions on sieves and the physical evolution of the mesoscopic structure of the particle assembly under various sieving conditions. The crucial effect of discrete particle motion on screening rate has been identified by a number of researchers, such as Jansen and Glastonbury ${ }^{5}$, Andrzejczak and Wodzinski ${ }^{11}$ and Rendell and Mullin ${ }^{12}$. These include how the particle segregation occurs in the material layer and how the undersize particles approach sieves and ultimately pass through apertures. The change of particle size distribution on a sieve during the transient process of screening alters the material composition at different layers and eventually affects the overall screening efficiency. To date there has been little reported in the literature concerning the study of these phenomena either by advanced measuring techniques or by modern computational tools.

This paper presents a mathematical simulation for the study of separation of smaller impurities from granular crop 
seeds, which complements an on-going research programme investigating particle breakage ${ }^{13}$ and separation of wheat grains and their middle products (broken kernels) in a milling plant. A two-dimensional transient model has been developed to calculate the motion of discrete particles on sieves using the Discrete Element Method (DEM) or the Discrete Element (DE) modelling technique ${ }^{14}$. Computational experiments have been conducted to examine the undersize particle motion across material layers and through apertures of an inclined screen with mechanical vibration, for a binary mixture of $6 \mathrm{~mm}$ soybeans and $2 \mathrm{~mm}$ mustard seeds. The study has focused on the influence of particle bed depth on undersize particle segregation across material layers. The screening rates and the required screen length at different feeding rates or bed depths are discussed in relation to the discrete particle motion on the screen.

\section{MATHEMATICAL MODEL}

\section{The Discrete Element Method (DEM)}

Pioneering work in the application of the DEM modelling was initially carried out by Cundall and Strack ${ }^{15}$ to model the behaviour of dense solid assemblies in soil mechanics. Their work concentrated on the use of 'springs and dashpots' to represent particle interactions, as shown in Figure 1.

This concept, which expresses the interaction with the use of a spring, dash-pot and friction slider analogy, has been adopted in most of the current DEM applications in particulate flows (e.g. Tsuji et al. ${ }^{16}$ ). Particles are usually assumed to be cohesionless elastic bodies and the microscopic particle-particle and particle-boundary interactions are calculated with the evolution of particle trajectories. Cohesive and inter-particle forces may also be considered as required by more complex applications. (see discussions by Thornton and $\mathrm{Yin}^{17}$.)

The contact force between impacting particles is split into a normal force $F_{n}$ and a tangential force $F_{t}$ :

$$
\begin{gathered}
F_{n}=-K \delta_{n}-\eta v_{n} \\
F_{t}=-K \delta_{t}-\eta v_{t}
\end{gathered}
$$

where $\delta_{n}$ and $\delta_{t}$ are particle displacements in the normal and tangential directions, $v_{n}$ and $v_{t}$ are the relative velocities, $K$ is the stiffness of the spring and $\eta$ is the coefficient of viscous dissipation (same values are used for both normal and tangential directions).

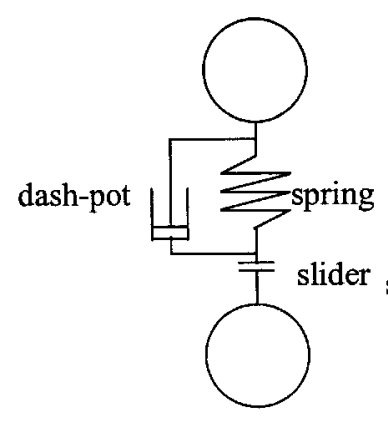

(a)

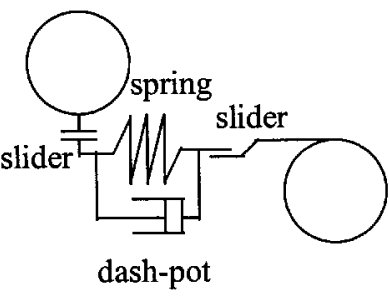

(b)
Figure 1. Models of contact forces: (a) normal force; (b) tangential force.
If $F_{t}$ is bigger than the limiting frictional force, then the particles slide over each other and the tangential force is calculated using the frictional coefficient $f$ :

$$
F_{t}=-f F_{n}
$$

Ideally, real particle stiffness based on actual Young's module of the modelled crop seeds is employed and the contact forces are calculated by the Hertzian contact theory rather than a linear relationship by the Hooke's law as shown in equations (1) and (2). However, this requires a much smaller size of time step to update a collision, which is beyond the power of current computing speed. Seville et $a{ }^{18}{ }^{18}$ stated that the linear spring model is the simplest mathematical form and is fairly widely used. They suggested that precise details of the contact mechanics may not be necessary, since in most real granular flow systems, particles are irregular and rough, and it is therefore unnecessary to model granular flow with ideal Hertzian contact. In addition, Tsuji et al. ${ }^{16}$ expressed that assuming a smaller value for the particle stiffness, thus allowing a larger time step, can still produce realistic particle motion while reducing the computation time. In their model, a reduced value of stiffness $K$ at $800 \mathrm{~N} \mathrm{~m}^{-1}$ was used in modelling fluidized bed and solids plug flow. This value has been found very sensitive in determining particle collisions after a number of trial runs. It was difficult to implement when modelling more severe interactions with high particle relative velocity ( $\mathrm{Li}$ and $\mathrm{Mason}^{14}$ ) because of the excessive contact deformation. In this study, considering the nature of the vibrational screening process and the computer resources conveniently available (a PC with a $1 \mathrm{GHz} \mathrm{CPU}$ ), a high stiffness of $3 \times 10^{5} \mathrm{~N} \mathrm{~m}^{-1}$ is used for particle-particle interactions and a value of $6 \times 10^{5} \mathrm{~N} \mathrm{~m}^{-1}$ for particle-wire collisions. These values are evaluated by conducting tests using a series size of time steps ranging from $1 \times 10^{-7}$ to $1 \times 10^{-5}$ second. A time step of equal to or less than $5 \times 10^{-7}$ second has been found sufficient to produce repeatable results without excessive particle motion caused by unrealistic particle collisions. This agrees with the suggestion made by Seville et al. ${ }^{18}$, who recommend that the selection of time step should be based on trial runs with different values until a reasonable and stable result came out.

The coefficient of viscous dissipation $\eta$ is calculated in accordance with Tsuji et al.'s ${ }^{16}$ analysis, who related it to the coefficient of restitution, which is one physical property of particles and can be easily measured experimentally. It is also noted that the coefficient of restitution given in Table 1 is not used for calculating particle velocity before and after collision but only used for determining the above coefficient of viscous dissipation. Different values of viscous dissipation $\eta$ and factional coefficient $f$ have also been tested but they are not as sensitive as the value of stiffness $K$ and the size of time step.

By knowing the various forces (contact and gravitational forces) acting on particles, the velocity and the trajectory of each individual particle are computed by integration with time so that the evolution of each particle is known. This allows all particles to be registered in a predefined domain and, therefore, the interactions between particles and with boundaries can be precisely calculated using the local particle and boundary properties.

DEM modelling has been widely adopted in particulate flow systems, such as fluidized beds ${ }^{16}$ and hopper flows ${ }^{19}$. 
Table 1. Summary of modelling conditions.

\begin{tabular}{|c|c|c|c|}
\hline Screen: & & & \\
\hline Wire diameter, mm & 1 & & \\
\hline Aperture width, mm & 2.5 & & \\
\hline Screen length, mm & 1000 & & \\
\hline Declination, degrees & 15 & & \\
\hline Vibration: & & & \\
\hline Amplitude, mm & 4 & & \\
\hline Frequency, rpm & 1620 & & \\
\hline $\begin{array}{l}\text { Motion (perpendicular } \\
\text { to screen surface) }\end{array}$ & Circular rotation & & \\
\hline Mixture: & & & \\
\hline Material & $\begin{array}{l}\text { Soybean and } \\
\text { Mustard seed }\end{array}$ & & \\
\hline Particle density, $\mathrm{kg} \mathrm{m}^{-3}$ & 1200 & & \\
\hline $\begin{array}{l}\text { Stiffness } K \text { for collisions } \\
\text { between seeds, } \mathrm{N} \mathrm{m}^{-1}\end{array}$ & $3 \mathrm{E}+5$ & & \\
\hline $\begin{array}{l}\text { Stiffness } K \text { for collisions } \\
\text { between wire and } \\
\text { seeds, } \mathrm{Nm}^{-1}\end{array}$ & $6 \mathrm{E}+5$ & & \\
\hline $\begin{array}{l}\text { Coefficient of restitution } \\
\text { (for both seeds and wire) }\end{array}$ & 0.6 & & \\
\hline $\begin{array}{l}\text { Coefficient of friction } f \\
\text { (for both seeds and wire) }\end{array}$ & 0.3 & & \\
\hline Particle size/diameter, mm & $6 \& 2$ & & \\
\hline $\begin{array}{l}\text { Ratio by particle number } \\
\text { between two sizes }\end{array}$ & $1: 1$ & & \\
\hline Ratio by particle volume & $27: 1$ & & \\
\hline Mass flow rate: & Test 1 & Test 2 & Test 3 \\
\hline $\begin{array}{l}\text { Feeding length (approximate, } \\
\text { along } \mathrm{x} \text { axis, } \mathrm{mm} \text { ) }\end{array}$ & 60 & 30 & 20 \\
\hline $\begin{array}{l}\text { Feeding rate: particle } \\
\text { number per second }\end{array}$ & 1500 & 700 & 400 \\
\hline $\begin{array}{l}\text { Calculated rate assuming a } \\
\text { screen width of } 0.8 \mathrm{~m}, \mathrm{th}^{-1}\end{array}$ & 50.7 & 23.6 & 13.5 \\
\hline
\end{tabular}

Seville et al. ${ }^{18}$ summarize the basic advantage of this method that it simulates effects at particle level. Individual particle properties, such as size and shape variation, can be specified directly and the assembly response is a direct output from the simulation. There have been a few DEM applications in cereal process engineering reported in the literature. Rong et $a l .{ }^{20}$ and Lu et $a l^{21}$ studied the flow behaviour of grains in bins and Sakaguchi et al. ${ }^{22}$ built a DEM model for the study of shear behaviour in a grain assembly. More recently, Sakaguchi et $a .^{23}$ extended their work to the shaking separation of paddy rice (unhusked) and brown rice (husked) in a separation box with solid walls. The distinction of the work presented in this paper lies in the implementation of a vibrating apertured screen as discussed in the following context.

\section{Modelling the Screening Process}

In a particulate flow system, such as in pipe or hopper flows, boundaries usually comprise a solid wall and an open inflow and outflow. Although internal boundaries may be defined in a Computational Fluid Dynamics (CFD) calculation, such as placing fins in a fluid field in PHOENICS (CFD software package developed by CHAM, UK), these boundaries are commonly regarded as solid walls. In a sieving operation, the key boundary is either a perforated wall or a woven mesh that provides apertures allowing undersize particles to pass through. Mechanical agitation (such as vibration) and screen inclination are usually employed to enhance the flowability of the material and to improve the screening rate.

Based on the model developed for gas-solids flows through pipes using a coupled approach by CFD and DEM modelling ${ }^{14}$, the computer program has been further developed to simulate particle motions on a sieving screen surface. The current implementation of the DEM model in sieving has focused on the definition of an apertured boundary and the algorithm for allowing particles to pass through the apertures or to rebound when approaching the screen surface. This has currently been constructed by placing a group of particles with the properties of the wires used for weaving the screen to form the configuration of the apertured screen surface as described in Table 1. These particles (wires) are allowed to vibrate to model the movement of a mechanically agitated screen. Other methods, such as a format with intervals of flat walls and holes to represent a perforated screen surface, will be considered in future applications. The interactions with interstitial gas flow (CFD calculation) have been switched off in the current simulations but may be of further research interest when modelling screening processes where airflow is of significance, such as in the purifiers of a flour milling plant.

\section{COMPUTER SIMULATIONS AND ANALYSES \\ Conditions of Modelling}

Simulations were conducted to model the separation of dry particles on a vibrating inclined screen $(1 \mathrm{~m}$ long and 15 degree declination) made from woven steel wires, currently with a wire diameter of $1 \mathrm{~mm}$ and an aperture width of $2.5 \mathrm{~mm}$. The study used a binary mixture, which consisted of two different agricultural products: soybeans and mustard seeds. Both crops were assumed to be spherical in shape with an average particle size of $6 \mathrm{~mm}$ (majority from 5 to $7 \mathrm{~mm}$ in natural products) for the soybeans and $2 \mathrm{~mm}$ (majority from 1.5 to $2.5 \mathrm{~mm}$ naturally) for the mustard seeds respectively. They were modelled as circular discs in the current two-dimensional domain. The particle densities of these two products were assumed to be the same, i.e. $1200 \mathrm{~kg} \mathrm{~m}^{-3}$. The separation of these two products may represent the essential cleaning operation in typical cereal handling and processing plants.

The calculation domain and the boundary conditions used in the model are specified to match those in an experimental system under development, which is illustrated in Figure 2 (the size in the third dimension, $0.4 \mathrm{~m}$, is not shown). Particles are fed onto the screen by gravity via a divert slot underneath the feeding hopper. The mass flow rate of solids being loaded onto the screen surface is controlled by an adjustable slide to regulate the slot opening and hence the feeding thickness. Undersize particles passing through apertures along a $1 \mathrm{~m}$ screen were collected by specially built cells underneath the screen, which allowed a direct analysis of screening rate (here defined as the number of particles passing through a certain length of screen during a period of time) along the screen. Overflowing particles are allowed to leave the domain when particles pass the end of the screen. Particle interactions with the boundary wall in the third dimension have been neglected in the current model.

In the model, an initial particle velocity, which was calculated in accordance with the actual feeding layout 


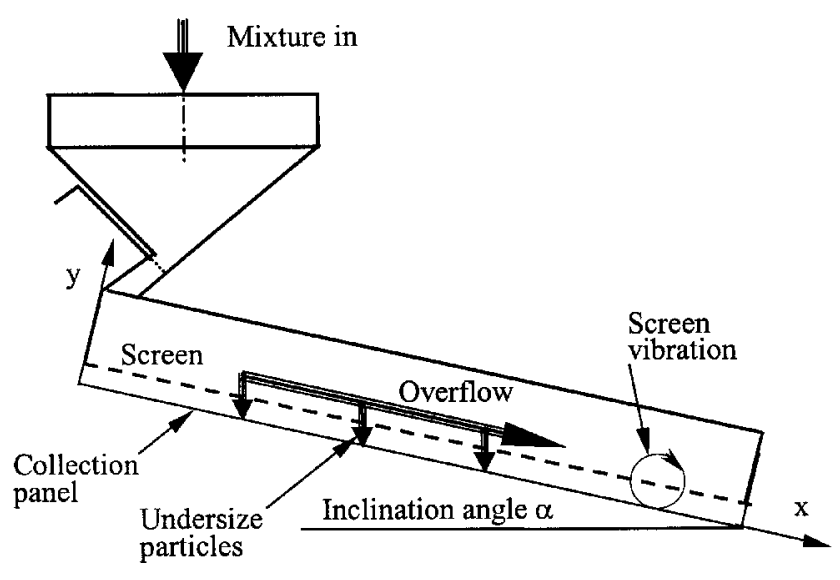

Figure 2. Schematic layout of the experimental device for the study of solids screening.

(height and angle), was assigned for all particles. Currently the particle velocities in the two axial directions, $x$ and $y$, are assumed to be $v_{x}=0$ and $v_{y}=-0.5 \mathrm{~m} \mathrm{~s}^{-1}$. In accordance with the layout of the test rig, the mass flow rate of particles allowed onto the screen is controlled by the feeding material thickness, which corresponds to the opening of the feeding slot. In addition, a specific time is assigned for each particle to enter the calculation domain so that a predefined mass flow rate can be exactly matched.

The selection of screen movement is based on the analysis of Kelly and Spottiswood ${ }^{24}$, who relate the amplitude and frequency to the size of the screen aperture. For the $2.5 \mathrm{~mm}$ aperture used in this study, an amplitude of $4 \mathrm{~mm}$ and a frequency corresponding to $1620 \mathrm{rpm}$ (flow rotation, i.e. rotating clockwise as shown in Figure 2 to enhance particle flow down the screen) were chosen as recommended by Kelly and Spottiswood.

A summary of the conditions and relevant parameters used in the simulations are listed in Table 1. An estimated bulk feed rate is given for each test case, which demonstrates the approximate capacity in case of a $0.8 \mathrm{~m}$ screen width (equivalent to industrial scale). This rate is calculated based on the number of particles that can be loaded in a three dimensional domain. The particle number is determined by multiplying the number of particles fed per second in the two-dimensional domain with the maximum number of particles ( $6 \mathrm{~mm}$ soybean) that can be placed in contact in a row over the entire $0.8 \mathrm{~m}$ screen width.

It is noted that the present study assumes a monosize particle distribution for the two agricultural products, which do not fully represent the real nature of the process. However, deviations may be kept minimal by carefully preparing the sample materials to obtain a narrow particle size distribution around the specified particle diameters. Further work will focus on the implementation of the DEM simulation to more complex engineering problems considering a full range of particle size distributions and shape factors, such as the cleaning of wheat grains, and the development of the experimental system.

\section{Screening Process of Particles}

The efficiency of a screening operation is dependent upon the motion of particles on and through the apertured screen.
Wills $^{25}$ states that there are two main requirements, which must be satisfied for efficient screening of particulate materials. The first is the conveyance of particles to the mesh apertures and their presentation in as many attitudes as possible. The second is to ensure that particles pass the mesh apertures without blinding (blockage of screen aperture by particles). It is an especially important aspect in industrial screening, where the screen movement must encourage segregation and prevent blinding ${ }^{26}$. (In the present study, the large particles used, $6 \mathrm{~mm}$ soybeans, are much bigger than the size of screen aperture, $2.5 \mathrm{~mm}$. Blinding is not expected a serious problem as in this particular situation in real screening process and as shown in the figures presented in the following section.)

Particle segregation in a bulk assemblage of particles has been extensively studied in particulate systems ${ }^{27,28}$. This is a major defect in many particulate solids flow systems such as mixing and hopper flow, where a high homogeneity of the mixture needs to be achieved. However, the stratification (usually referring to segregation in the vertical direction) of particles according to sizes has long been recognized as a positive mechanism in particle separation ${ }^{29}$. On a screen surface, as shown in all figures in the following section, smaller particles tend to gather into groups and fill gaps between islands formed by large particles. This is a typical segregation phenomenon in any particulate flow and the tendency of small particles moving towards the screen through the gaps between large particles is the key influencing the screening rate. Further details of particle segregating in material layers at various bed depths and passing through apertures are discussed in the following context.

\section{Depth of Particle Bed}

Kelly and Spottiswood ${ }^{24}$ state that although an exact depth of particle bed is hard to specify, it is apparent that there is an optimum bed depth that produces the maximum screening rate. Three distinct flow regions are identified as particle loading is increased. Region I is characterized by insufficient particles to form a monolayer on the screen. This results in a low screening rate because the particles tend to have excessive unrestrained motion, and because the full screen surface is not being fully utilized. In Region II, there is at least a monolayer of particles over the surface and the maximum through rate occurs. Under these conditions the closeness of the particles tends to restrain the bouncing action and potential passing material has maximum exposure to the screen apertures. The lowest screening rate occurs in region III, that is, when the bed is excessively deep and presentation for passage is severely restricted, not only because of the quantity of oversize material is high, but because of insufficient segregation in the material layers.

Since most efficient screening occurs in Region II, it is desirable to maintain this region over as much of the screen surface as is possible. This study used the advanced computational technique of DEM modelling to quantify the optimum bed depth for a particular screening operation as described in Figure 2. Three tests were conducted for the separation of a mixture of soybeans and mustard seeds, each of which uses similar modelling conditions except for a different solids loading rate as defined in Table 1. Figure 3(a) shows the discrete particle motion (a snapshot at an instant time when the flow reaches a quasi-equilibrium state) on the 

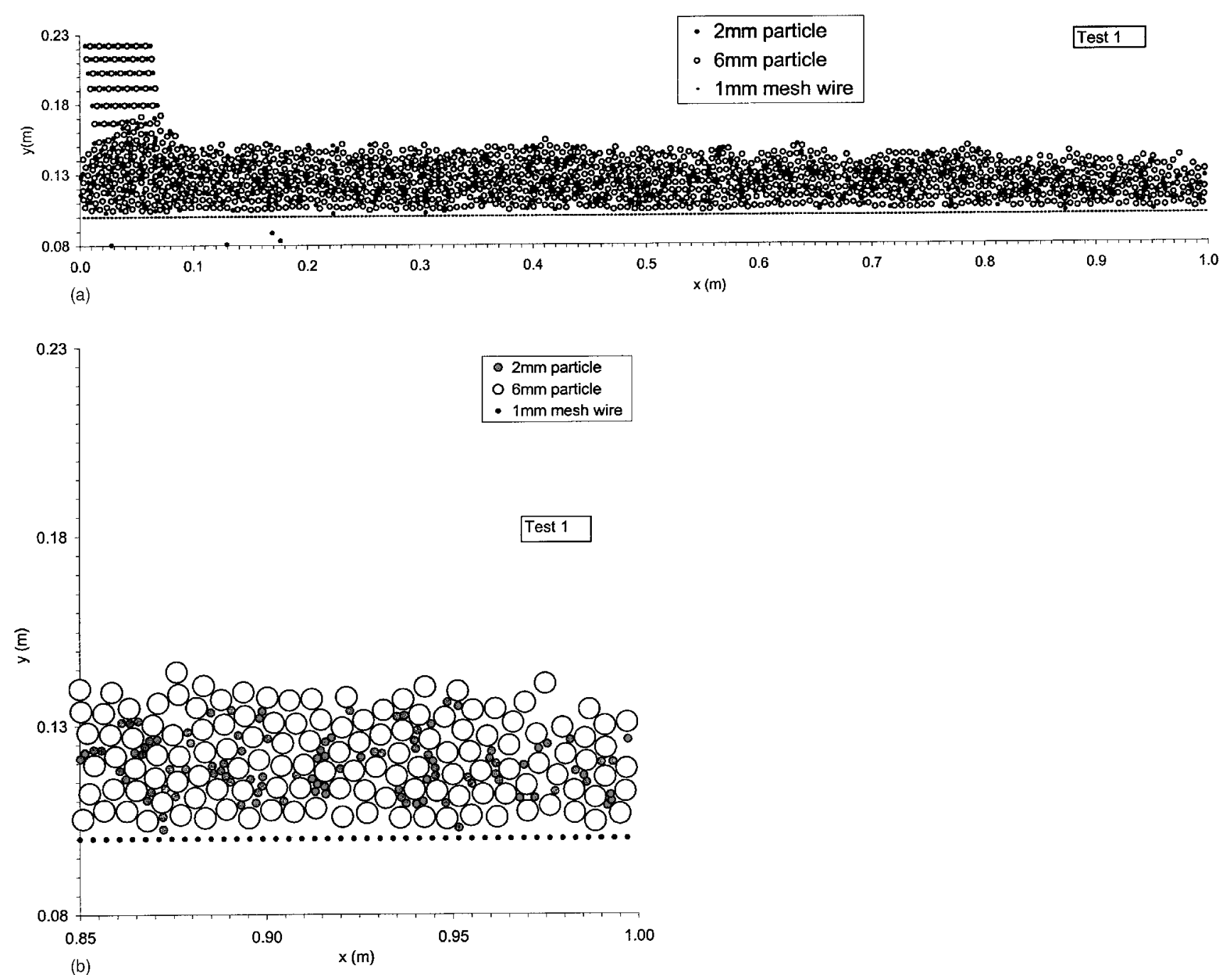

Figure 3. (a) Particle motion on screen in Test 1 -Overview (Note: The co-ordinates shown in figures from 3(a) to 5(b) correspond to the screen layout in Figure 2, which has a 15 degree declination); (b) Particle motion on screen in Test 1 -Amplified.

screen at a high solids loading rate-Test 1 . The average depth of particle bed in this test is above $50 \mathrm{~mm}$, which is more than 8 times the size of large particles and 20 times the size of screen apertures. Obviously the particle bed is too thick for small particles to segregate effectively toward the screen apertures. An amplified diagram, Figure 3(b), shows a clearer picture of the particle assembly at the end of the screen (from $0.85 \mathrm{~m}$ to $1.00 \mathrm{~m}$ ). This shows that a large number of undersize particles remain on the screen even after travelling the whole screen length. This test can well represent Region III discussed above.

Figure 4(a) shows the particle motion at a reduced solids loading rate, i.e. Test 2 , with about half the loading of Test 1 . Although the bed depth in this test has been decreased to about $40 \mathrm{~mm}$ and a much better screening efficiency (here defined as the percentage of mass of undersize particles removed by screening to the total mass of undersize particles in the feeding material) has been achieved compared to Test 1 , there are still some undersize particles passing over at the end of the screen, as shown in Figure 4(b). A further reduction of the solids loading rate has been tested in Test 3 with about one third solids loading of Test 1 . In this case, as shown in Figure 5(a) and 5(b), the particle bed depth still remains over $30 \mathrm{~mm}$, about 5 times the size of large particles and 12 times the size of screen apertures, because the particle assembly on the screen becomes much looser than those in Tests 1 and 2. Most undersize particles have segregated to the screen surface and passed through apertures within about $0.4 \mathrm{~m}$ at the front section of the screen. It also shows that the $1 \mathrm{~m}$ screen length was long enough to ensure the highest screening efficiency (100 percent separation), which means no undersize particle has passed over and joined the overflow of large particles at the end of the screen.

A statistical analysis of the relative screening rate, i.e. percentage of through rate to input flow of undersize particles, along the screen is shown in Figure 6. In this analysis, the whole $1 \mathrm{~m}$ screen has been divided into 10 sections, each with a length interval of $0.1 \mathrm{~m}$. Particles passing through each section were monitored for a period of two seconds at quasi-equilibrium flow state. The relative screening rates for the three test cases all show a higher rate near the inlet and the shape of these screening curves in Figure 6 follows the trend analysed by Subasinghe et al. ${ }^{9}$. A much higher screening rate near the inlet is shown in Test 3 but this follows a sharp decrease after $0.3 \mathrm{~m}$ downstream 

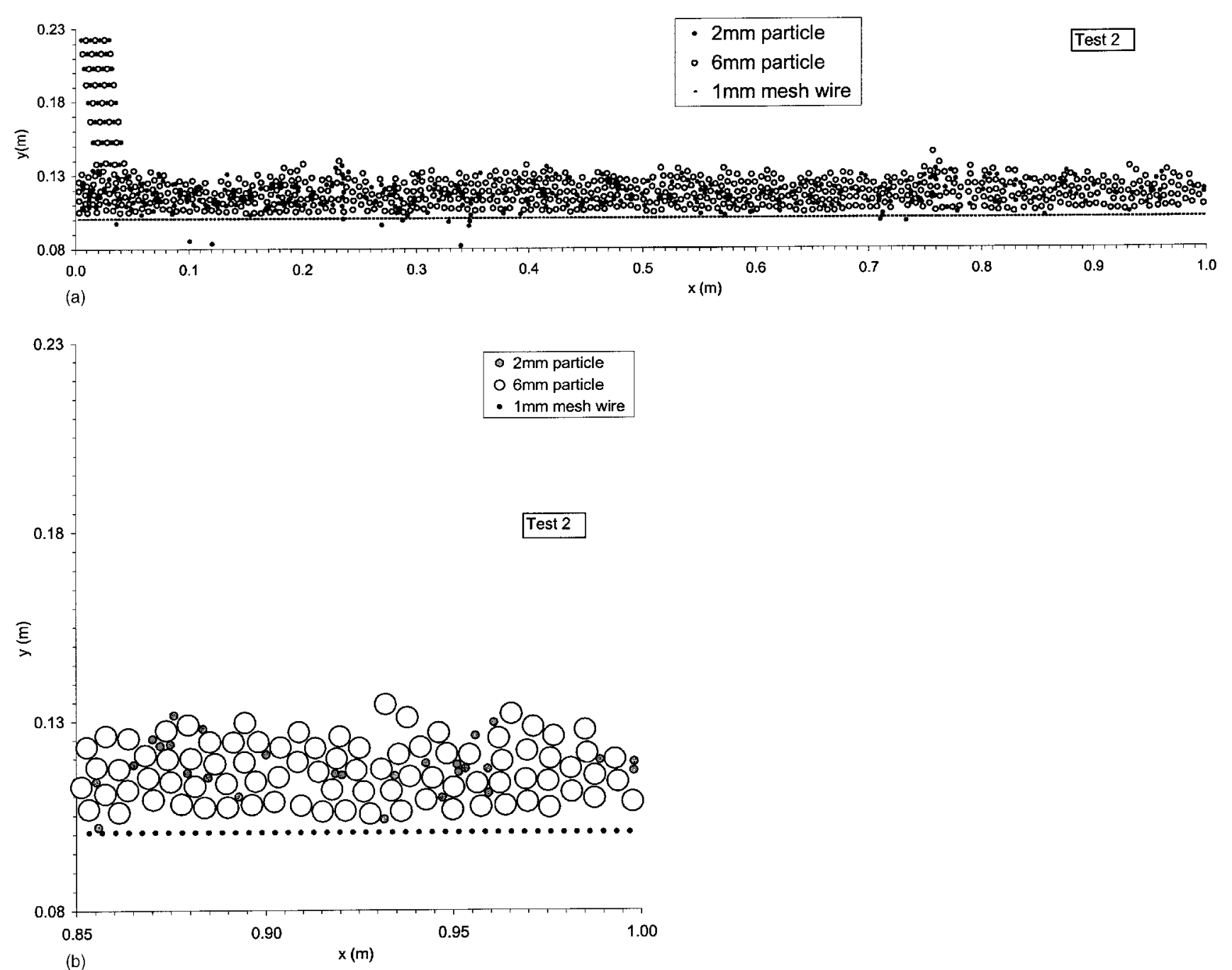

Figure 4. (a) Particle motion on screen in Test 2-Overview; (b) Particle motion on screen in Test 2-Amplified.

and, obviously, this is due to the relatively low proportion of undersize particles on the screen (by reference to the following Figure 7). Cumulative curves (indicated by Cum.) are also plotted in Figure 6, which show the difference of the screening progress along the screen length and the overall screening efficiency (represented by the last data point) between the three tests. Test 3 , with a $100 \%$ cumulative rate by the end of the screen (actually from section $0.7 \sim 0.8 \mathrm{~m}$ ), may be regarded as the nearest optimum bed depth for this particular operation if the highest screening efficiency is required.

To examine particle segregation in material layers, the mean value of particle position in the $y$ direction has been analysed. Similar to the above analysis for the screening rate, particles on the screen were monitored in every $0.1 \mathrm{~m}$ screen section for a period of two seconds at quasiequilibrium flow state. The plots of mean $y$ value for both large and small particles on the screen, as seen in Figure 7 (Test 1/2/3-large or small), show a very similar average height for both particle sizes in all the three test cases. This indicates a poor stratification in the material layers on the screen. However, this analysis did not take into account the amount of particles already depleted through the screen after being conveyed near the screen surface. Therefore, relative proportions (by number) between small and large particles are also presented in Figure 7 (Test 1/2/3-R). It is obvious that a very sharp drop of small particle numbers at section $0-0.2 \mathrm{~m}$ in Test 3 corresponds to the high screening rate in this region as shown in Figure 6. This implies a prompt segregation of small particles towards the screen. For Tests 1 and 2, a gradual drop of small particle numbers is shown along the screen length. In these two cases, poor stratification dominates and this has led to a low screening efficiency, though small particles near the screen have also been effectively depleted and passed through apertures without forming a stratified layer.

\section{Screen Length}

As discussed above, the screen length required for a particular screening operation is dependent upon the depth of particle bed. To maintain a certain overall screening efficiency, a deeper particle bed, i.e. a higher loading rate, usually requires a longer screen length. From the cumulative curves in Figure 6, it can be seen that it would require a much longer screen length to achieve a higher screening efficiency with a bed depth as thick as in Test 1 . However, the relatively low proportion of small particles left on the 

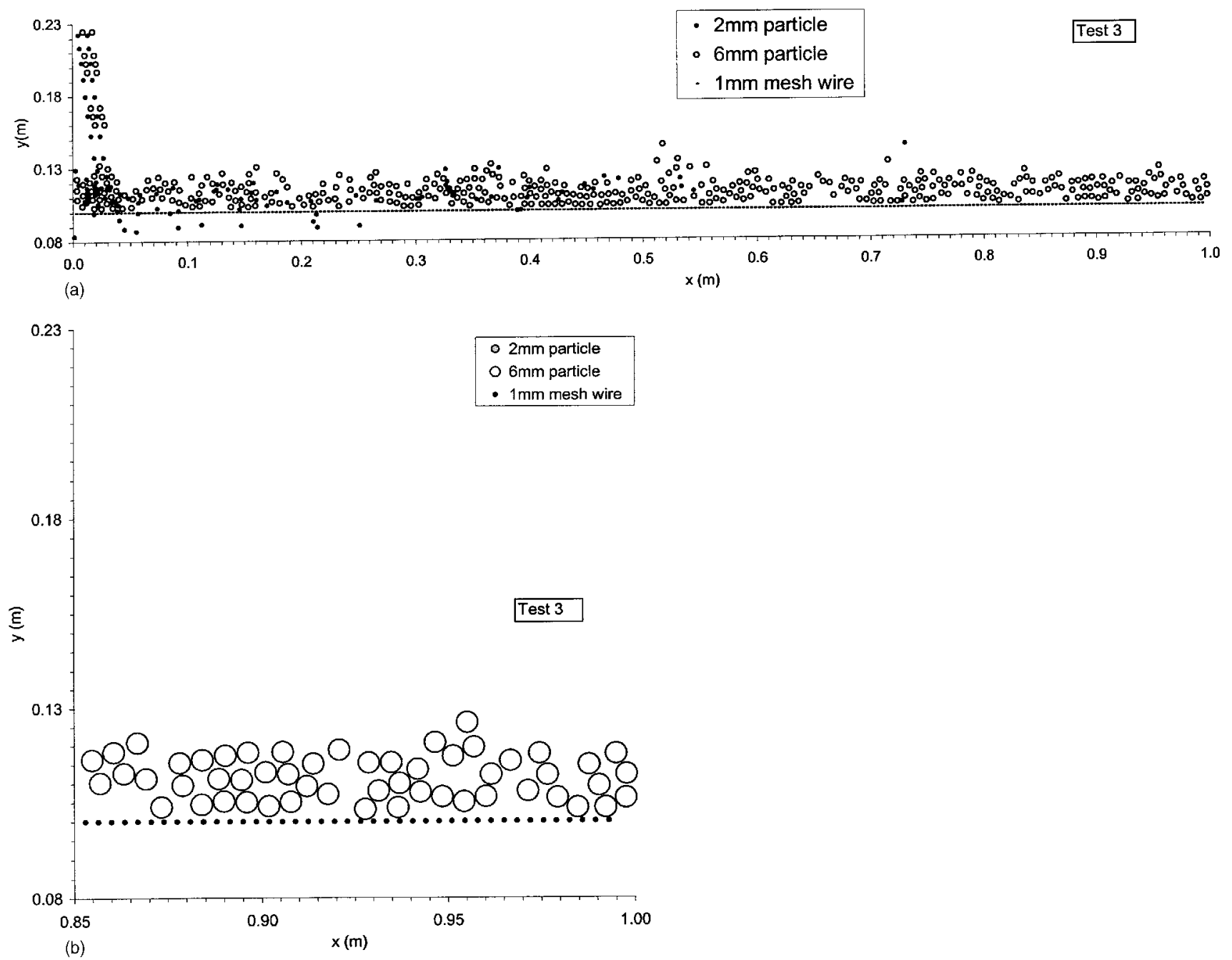

Figure 5. (a) Particle motion on screen in Test 3-Overview; (b) Particle motion on screen in Test 3-Amplified.

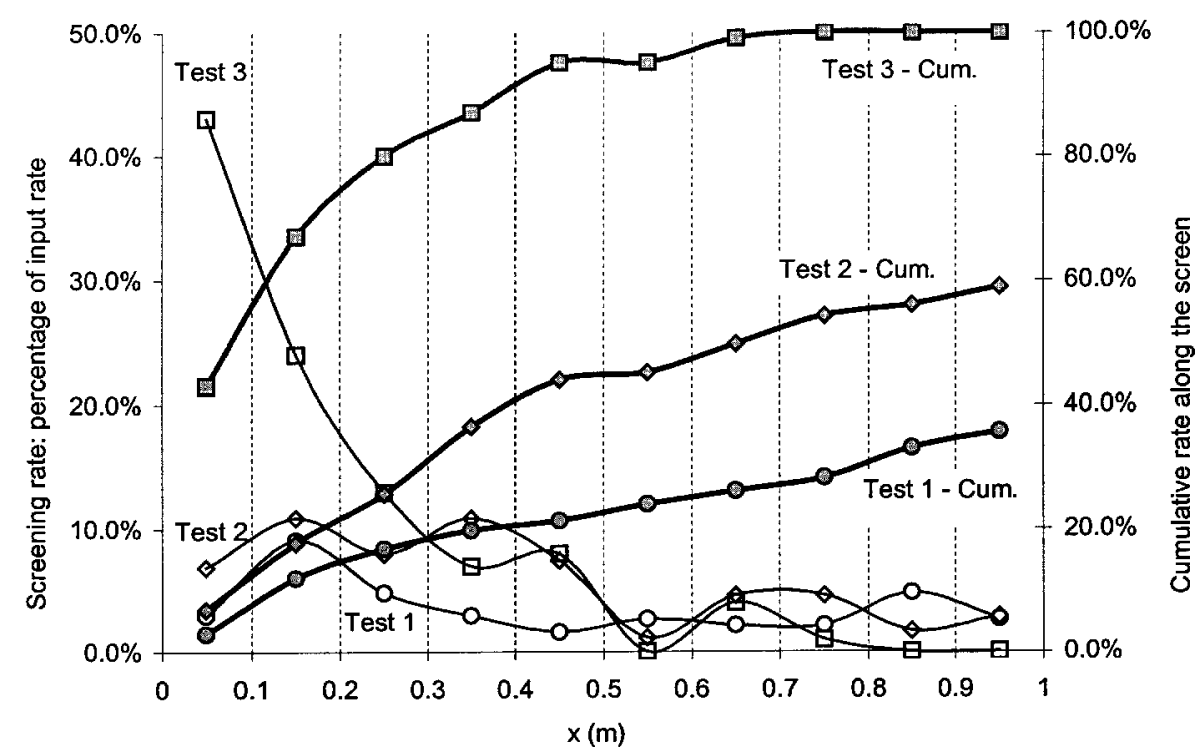

Figure 6. Relative and cumulative screening rates along the screen. 


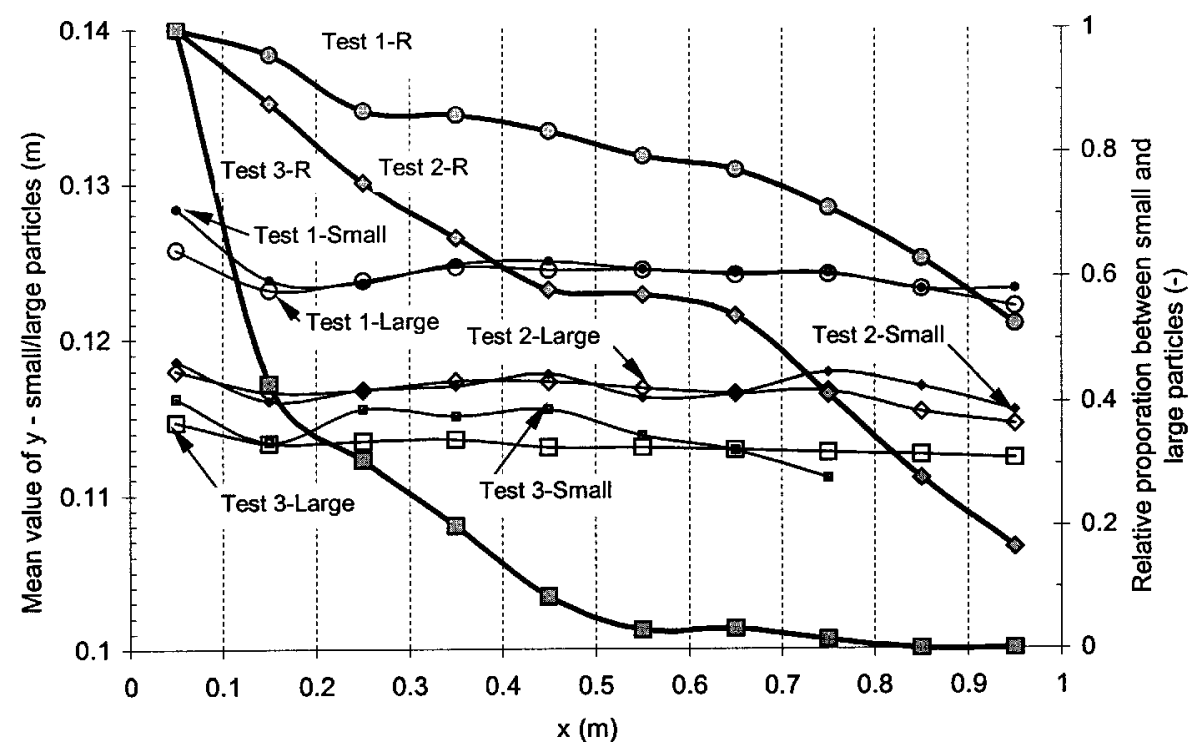

Figure 7. Mean value of $y$ and relative proportion between small and large particles.

screen at the end in Test 2, as shown in Figure 7, shall be able to pass the apertures if the screen length is further extended. For Test 3 , as discussed before and quantitatively shown in Figures 6 and 7, the $1 \mathrm{~m}$ screen has been long enough to achieve a $100 \%$ removal of small particles.

Higher screening efficiency is a desire for any screening operations. Nevertheless, this does not mean that the highest screening efficiency, i.e. $100 \%$ removal of undersize particles, is a necessity for all screening operations. In the multi-deck plan-sifter of a milling plant, for instance, the screening processes consist of a zigzag series of flow routes from the top deck to the bottom. The multi-deck layout actually elongates the overall screening length and the screening efficiency of individual sieve deck may vary due to the change of composition in the overflow mixture. For a onethrough (one screen deck) screening operation, usually a certain level of screening efficiency, say $90 \%$, is defined for a particular mixture. A higher efficiency is always possible but may not be economical. As a result, in any screening operation, the balance between solids loading rate, screen length and screening efficiency must be carefully evaluated.

\section{CONCLUSIONS}

The DEM modelling technique has been used to study the separation of particulate solids during the cleaning and sorting of cereal foods. Simulations modelling a scheduled experimental operation for the separation of soybeans from mustard seeds have demonstrated the crucial effect of particle bed depth on particle segregation in material layers and hence on screening efficiency. The required screen length at different solids loading rates is discussed in relation to the discrete particle motion on the screen. The DEM simulations have provided an insight into the separation process at discrete particle level. For a screening system involving granular materials, it has demonstrated that the critical feeding rate or bed depth for the most effective screening operation can be determined via conducting the DEM simulation. Further work will focus on the implemen- tation of advanced experimental techniques to measure the process and to validate the model.

\section{REFERENCES}

1. Wang, Y. J., Chung, D. S., Spillman, C. K., Eckhoff, S. R., Rhee, C. and Converse, H. H., 1994, Evaluation of laboratory grain cleaning and grading separating equipment, Part I, Trans ASAE, 37(2): 507-573.

2. Scott, J. H., 1951, Flour Milling Processes, 2nd edition (Chapman and Hall Ltd, London, UK).

3. Coulson, J. M. and Richardson, J. F., 1991, Chemical Engineering V2Particle Technology and Separation Process, 4th edition (Pergamon, Oxford, UK).

4. Standish, N., 1985, The kinetics of batch sieving, Powder Tech, 41: $57-67$.

5. Jansen, M. L. and Glastonbury, J. R., 1967/1968, The size separation of particles by screening, Powder Tech, 1: 334-343.

6. Standish, N. and Meta, I. A., 1985, Some kinetic aspects of continuous screening, Powder Tech, 41: 165-171.

7. Standish, N., Bharadwaj, A. K. and Hariri-Akbari, G., 1986, A study of the effect of operating variables on the efficiency of a vibrating screen, Powder Tech, 48: 161-172.

8. Kaye, B. H. and Robb, N. I., 1979, An algorithm for deducing an effective sieve residue from the rate of powder passage through a sieve, Powder Tech, 24: 125-128.

9. Subasinghe, G. K. N. S., Schaap, W. and Kelly, E. G., 1989, Modelling the screening process: A probabilistic approach, Powder Tech, 59: $37-44$.

10. Grozubinsky, V., Sultanovitch,E. and Lin, I. J., 1998, Efficiency of solid particle screening as a function of screen slot size, particle size, and duration of screening-The theoretical approach, Inter Mineral Proc, 52: 261-272.

11. Andrzejczak, P. and Wodzinski, P., 1994, Model of Screening in the layer, Powder Hand Proc, 6: 263-272.

12. Rendell, M. and Mullin, J. W., 1968, The flow of particles through a screen aperture, IChemE Symposium Series, 29: 55-65.

13. Campbell, G. M. and Webb, C., 2001, On predicting roller milling performance Part I: The breakage equation, Powder Tech, 115(3): 234-242.

14. Li, J. and Mason, D. J., 2000, A computational investigation of transient heat transfer in pneumatic transport of granular particles, Powder Tech, 112(3): 273-282

15. Cundall, P. A. and Strack, O. D., 1979, A discrete numerical model for granular assemblies, Geotechnique, 29(1): 47-65.

16. Tsuji, Y., Tanaka, T. and Ishida, T., 1992, Lagrangian numerical simulation of plug flow of cohesionless particle in a horizontal pipe, Powder Tech, 71: 239-250. 
17. Thornton, C. and Yin, K. K., 1991, Impact of elastic spheres with and without adhesion, Powder Tech, 65: 153-166.

18. Seville, J. P. K., Tuzun, U. and Clift, R., 1997, Processing of Particulate Solids (Blackie Academic and Professional, London, UK).

19. Langston, P. A., Tuzun, U. and Heyes, D. M., 1995, Distinct element simulation of granular flow in 2D and 3D hoppers: Dependance of discharge rate and wall stress on particle interactions, Chem Eng Sci, 50(6): 967-987.

20. Rong, G. H., Negi, S. C. and Jofriet, J. C., 1995, Simulation on flow behaviour of bulk solids in bins. Part I and II, J Agric Eng Res, 62: 247-269.

21. Lu, Z., Negi, S. C. and Jofriet, J. C., 1997, A numerical model for flow of granular materials in silos: Part I, II and III, J Agric Eng Res, 68: 223-229; 231-236; 237-246.

22. Sakaguchi, E., Kawakami, S. and Tobita, F., 1994, Simulation on flowing phenomena of grains by distinct element method, AgEng'94 (Milan, Italy), Report No. 94-G-025.

23. Sakaguchi, E., Kawakami, S., Suzuki, M., Urakawa, T. and Favier, J. F., 1998, Effective use of DEM simulation for development of grain processing technology-Application to shaking separation phenomenon of paddy and brown rice, AgEng'98 (Oslo, Norway), Paper No. $98-F-021$.

24. Kelly, E. G. and Spottiswood, D. J., 1982, Introduction to Mineral Processing (John Willey \& Sons, New York, USA), pp 172 and 182.

25. Wills, B. A., 1997, Mineral Processing Technology, 6th edition (Butterworth-Heinemann, Oxford, UK), pp 187.
26. Williams, J. C. and Shields, G., 1967, The segregation of granules in a vibrated bed, Powder Tech, 1: 134-142.

27. Williams, J. C., 1976, The segregation of particulate materials-A review, Powder Tech, 15: 245-251.

28. Mosby, J., de Silva, S. R. and Enstad, G. G., 1996, Segregation of particulate materials-Mechanisms and testers, KONA, 14: 31-43.

29. Hudson, R. B., Jansen, M. L. and Linkson, P. B., 1968/1969, Batch sieving of deep particulate beds on a vibratory sieve, Powder Tech, 2: 229-240.

\section{ACKNOWLEDGEMENTS}

The authors acknowledge gratefully the Satake Corporation of Japan for their financial support of these studies.

\section{ADDRESS}

Correspondence concerning this paper should be addressed to Dr J. Li, Satake Centre for Grain Process Engineering, Department of Chemical Engineering, UMIST, PO Box 88, Manchester M60 1QD, UK. Email: jintang.li@umist.ac.uk

The manuscript was received 5 November 2001 and accepted for publication after revision 3 April 2002. 